\title{
Mühendislik Fakültesi Öğrencilerinin Programlamaya Yönelik Tutumları1
}

\section{Melih Derya Gürer²}

\section{Seyfullah Tokumaci ${ }^{3}$}

\section{Type/Tür:}

Research/Araştırma

Received/Geliş Tarihi:

January 6/6 Ocak 2020

Accepted/Kabul Tarihi:

November 23/ 23 Kasim

2020

Page numbers/Sayfa No:

1064-1082

Corresponding

Author/İletişimden

Sorumlu Yazar:

mdgurer@gmail.com

\section{$\checkmark$ iThenticate}

This paper was checked for plagiarism using iThenticate during the preview process and before publication. / $\mathrm{Bu}$ çalışma ön inceleme sürecinde ve yayımlanmadan önce iThenticate yazılımı ile taranmıştır.

Copyright () 2017 by Cumhuriyet University, Faculty of Education. All rights reserved.

\section{Öz}

Son on yılda programlama öğretimi ilköğretimden yetişkin eğitimine kadar geniş bir kitlede önem kazanmıştır. Fakat programlama mühendislik eğitiminde diğer bilim dallarına göre yeni bir konu değildir ve önemli bir yere sahiptir. Mühendislik fakültelerinde öğrencilerin programlama başarısını etkileyen önemli faktörlerden biri olan programlamaya yönelik tutumların belirlenmesi önemli bir konudur, ancak bu konu yeterince incelenmemiştir. Dolayisıyla bu çalışma, mühendislik fakültesi öğrencilerinin programlamaya yönelik tutumlarını incelemeyi amaçlamaktadır. Ayrıca çalışmada öğrencilerin programlamaya yönelik tutumlarının cinsiyete, bölüme ve programlama üzerine alınan ders sayısına göre farklılaşıp farklılaşmadığı incelenmektedir. $\mathrm{Bu}$ amaçla nicel araştırma yöntemlerinden biri olan tarama çalışması tasarlanmış ve bir devlet üniversitesinin mühendislik fakültesinde öğrenim görmekte olan 742 lisans öğrencisi çalışmanın örneklemini oluşturmuştur. Verileri toplamak için Bilgisayar Programlamaya Yönelik Tutum ölçeği kullanılmıştır. Verilerin analizinde ortalama ve standart sapma testlerinin yanı sıra parametrik olmayan testler ile gruplar arası karşılaştırmalar incelenmiştir. Betimsel istatistiklerle yapılan veri analizinde öğrencilerin genel olarak programlamaya yönelik yüksek düzeyde olumlu tutuma sahip oldukları sonucuna ulaşılmıştır. Öğrenciler bilişsel boyutta orta düzeyde tutuma sahipken duyuşsal ve davranışsal boyutta ise yüksek düzeyde tutuma sahiptir. Ayrıca parametrik olmayan istatistiksel test sonuçlarına göre öğrencilerin tutumu cinsiyete göre farklılık göstermezken bölümlerine ve programlama üzerine almış oldukları ders sayısına göre farklılaşmaktadır. Bilgisayar mühendisliği öğrencilerinin programlamaya yönelik tutumlarının diğer bölüm öğrencilerinin tutumlarından daha yüksek olduğu söylenebilir. Programlama üzerine alınan ders sayısı arttıkça programlamaya yönelik tutum da artmaktadır. Çalışmanın sonuçları doğrultusunda mühendislik fakültesi öğrencilerinin programlamaya yönelik tutumlarını geliştirmek için aldıkları programlama derslerinin sayısının artırılması tavsiye edilebilir.

Anahtar Kelimeler: Programlama, tutum, mühendislik fakültesi, cinsiyet, bölüm.

\section{Suggested APA Citation/Önerilen APA Atıf Biçimi:}

Gürer, M. D., \& Tokumacı, S. (2020). Mühendislik fakültesi öğrencilerinin programlamaya yönelik tutumlar1. Cumhuriyet International Journal of Education, 9(4), 1064-1082. http://dx.doi.org/10.30703/cije.671244

\footnotetext{
${ }^{1}$ Bu çalışma Seyfullah TOKUMACI'nın "Mühendislik fakültesi öğrencilerinin bilgisayar programlamaya ilişkin algılanan öğrenme düzeylerini yordayan faktörler" isimli tezinden üretilmiştir.

2 Dr. Öğr. Üyesi, Bolu Abant İzzet Baysal Üniversitesi, Eğitim Fakültesi, Bilgisayar ve Öğretim Teknolojileri Eğitimi Bölümü, Bolu / Türkiye. Assist. Prof. Dr., Bolu Abant Izzet Baysal University, Faculty of Education, Department of Computer Education and Instructional Technology, Bolu / TURKEY

e-mail: mdgurer@gmail.com ORCID ID: orcid.org/0000-0002-2627-7847
}

3 Öğr. Görevlisi, İzmir Bakırçay Üniversitesi, İzmir / Türkiye

Instructor, İzmir Bakırçay University, İzmir/Turkey

e-mail: s.tokumaci@gmail.com ORCID ID: orcid.org/0000-0001-5020-3189 


\title{
Engineering Students' Attitudes Towards Programming
}

\begin{abstract}
During last decade, programming education has gained importance in a wide range from primary education to adult education. However, programming is not a new topic in engineering education compared to other disciplines and it has an important place in engineering education. It is critical to determine the attitudes towards programming, which is one of the important factors that affect the students' programming success in engineering faculties. However, it has not been researched enough. Hence, the aim of this study was to investigate engineering students' attitudes towards computer programming. In addition, it was examined whether students' attitudes towards programming differ according to gender, department and number of courses on programming. With this aim, a survey study which is a type of quantitative research methods was adopted, and 742 higher education students studying at the engineering faculty of a state university in Turkey were the sample of this study. The data were collected through the Attitude towards Computer Programming Scale. The data were analyzed with descriptive statistics such as mean and standard deviation and nonparametric statistical tests. Using the descriptive statistics, it was found that engineering students had moderately high attitudes towards programming. Although students had middle level attitude at the cognitive dimension, they had moderately high attitudes at affective and behavioral dimensions. In addition, non-parametric tests indicated that although students' attitudes did not differ according to their gender, their attitudes differed according to their departments and the number of courses they took on programming. It could be concluded that Computer Engineering students' attitudes towards programming were found to be higher than the students of the other engineering departments. Moreover, it was found the more courses on programming taken, the higher the attitude toward programming. In line with the results of this study, the number of programming language courses taken by engineering faculty students might be increased to improve their attitudes towards computer programming.
\end{abstract}

Keywords: Programming, attitude, engineering faculty, gender, department

\section{Giriş}

Programlama eğitimi, yeni teknolojilerin hızla gelişmesi nedeniyle son on yılda büyük önem kazanmıştır. Amerika Birleşik Devletleri (ABD), İngiltere, Fransa, Japonya, Çin gibi gelişmiş ülkeler bilgisayar programlama öğretimi konusunda ciddi atılımlar gerçekleştirmekte, programlama öğretimini ilkokul seviyelerindeki öğrencilere uygulamak için kararlar almakta ve programlama becerisini geliştirecek etkinlikler ve yarışmalar düzenlemektedirler. Gelişmekte olan ülkelerde de etkili öğretim yöntemleri tartışılmakta ve dünyadaki bu eğilimi yakından takip etmek üzere tüm eğitim seviyelerinde programlama öğretimi için yeni öğretim programları geliştirilmektedir. Bu kapsamda Türkiye'de 2012 yılında yayınlanan 69 sayılı kararla 5. ve 6. sinıflarda sunulan "Bilişim Teknolojileri" dersi, "Bilişim Teknolojileri ve Yazılım" olarak güncellenerek derse yazılım ve programlamaya yönelik içerikler eklenmiş ve öğrencilere kodlama ve yazılıma yönelik eğitimler verilmeye başlanmıştır (Tebliğler Dergisi, 2012, s.471).

Programlama ilk ve ortaöğretim düzeyinde son on yıldır tartışılıyor olsa da yükseköğretim düzeyinde özellikle mühendislik eğitiminde daha uzun yıllardır tartışılan ve öğretilen bir beceridir. Wing (2008), pek çok bilim ve mühendislik disiplininin, doğada bulunan fiziksel süreçlerin matematiksel modellerinin muazzam bilgisayar simülasyonlarına dayandığını ifade etmektedir. Özellikle mühendislik 
alanındaki çalışmalar için geliştirilen çeşitli yazılımlar klasik ölçüm ve hesaplama araçlarını devre dışı bıraktığından mühendislik çalışmalarını bilgisayardan ve programlamadan bağımsız düşünmek günümüzde mümkün görünmemektedir. Dolayısıyla, programlama becerileri sadece bilgisayar bilimi alanında değil birçok mühendislik okulu için de gerekli görülmektedir (Zyda, 2009).

Bilgisayar programlama, herhangi bir mühendislik programının önemli ve ayrılmaz bir parçasıdır. Mühendislik fakültesi öğrencileri 1. ve 2. sınıflarında sayısal yaklaşımları kullanarak sorunları çözme görevi ile karşı karşıyadır. İyi programlama becerileri, bu problemleri kolayca çözmelerini sağlayacaktır (Naraghi ve Bahman, 2001). Bu yüzden mühendislik ve teknoloji öğrencilerinin üniversite eğitiminin ilk yıllarında temel bilgisayar programlama becerilerini öğrenmeleri önemlidir. Neredeyse tüm mühendislik programları, öğretim programlarının bir parçası olarak programlama hakkında temel bilgiler içerir. Programlama dillerine giriş dersi, bilgisayar mühendisliği, yazılım mühendisliği, bilgi sistemleri mühendisliğinin yanı sıra elektrik mühendisliği, endüstri mühendisliği, inşaat mühendisliği, makine mühendisliği gibi birçok mühendislik alanı için de önemli ve zorunlu olarak öğrencilerin alması gereken bir derstir.

Temel bilimler, sosyal bilimler, sağlık bilimleri gibi birçok bilime ilişkin disiplinin ve konunun öğretiminde olduğu gibi programlama öğretiminde de öğrenci tutumu araştırmacılar tarafindan üzerine durulması ve incelenmesi gereken konulardan biridir (Cetin ve Ozden, 2015). Tutum, en genel ifadeyle kişilerin, çevresindeki bireylere, nesnelere ya da olaylara yönelik sahip olduğu değerlendirmelerdir. Aiken'e (2002) göre tutum, belirli nesnelere, durumlara, kurumlara, kavramlara veya kişilere olumlu veya olumsuz şekilde karşılık vermeye yönelik öğrenilmiş bilişsel, duyuşsal ve davranışsal eğilimlerdir. Bu tanıma göre tutum, tutum nesnesi hakkındaki inançlardan oluşan bilişsel boyut, nesneye yönelik sahip olunan duygulardan oluşan duyuşsal boyut ve nesneye yönelik eylem eğilimlerinden oluşan davranışsal boyut olmak üzere üç boyuttan oluşmaktadır.

Bilgisayar programlama, yeni başlayan programcilar tarafından kolayca öğrenilen bir beceri değildir ve literatürde bilgisayar programlamanın öğrenilmesinde yaşanan zorluklarla ilgili çalışmalar bulunmaktadır (Abdunabi, Hbaci ve Ku, 2019). Öğrenciler temel kavramları anlamada zorluklar yaşamakta ve başlangıç düzeyindeki programlama derslerinde hatasız programlar yazmakta zorlanmaktadırlar (Dasuki ve Quaye, 2016). Bu zorluklar öğrencilerin programlama derslerinde başarısız olmaları ve programlamaya yönelik negatif veya düşük tutum geliştirmesi ile sonuçlanmaktadır. Eğitim araştırmacıları daha önce yapılan çalışmalar üzerine bir meta analiz çalışması yürüterek (Ma ve Kishor, 1997; Sölpük, 2017) tutum ile başarı arasında pozitif bir ilişki olduğu ve öğrencinin bir konuya yönelik tutumunun başarıya zemin hazırladığı sonucuna ulaşmışlardır. Olumsuz algı, motivasyon ve özellikle düşük tutum gibi psikolojik faktörler de programlamayı öğrenmeyi olumsuz yönde etkileyen faktörlerdir (Anastasiadou ve Karakos, 2011). Bilgisayar programlama üzerine yapılan araştırmalar da programlamaya yönelik tutum ile başarı arasındaki pozitif ilişkiyi vurgulamaktadır (Başer, 2013a; Lee, Kim ve Lee, 2017). Hatta Gurer, Cetin ve Ibrahim (2019), yapmış olduğu çalışmada akademik başarının programlamaya yönelik tutumu yordayan faktörlerden birisi olduğunu sonucuna 
ulaşmıştır. Bu nedenle programlama becerisini ve başarısını etkileyen programlamaya yönelik tutumun daha fazla araştırılması gerekmektedir.

Öğrencilerin programlama başarısı ile ilgili olan potansiyel faktörlerden birisi cinsiyettir. Kadınların bazı kültürel ve çevresel sebeplerden dolayı bilgisayarla ilgili işlerde ve bilgisayar bilimleri dallarında yeterince temsil edilmediği ileri sürülmektedir (Doube ve Lang, 2012; Singh, Allen, Scheckler ve Darlington, 2007). Amerika Birleşik Devletleri'nde, 2013 yılında üniversiteye yeni kayıt yaptıran kadınlar arasında bilgisayar bilimi dalında yüksek lisans yapmak isteyenlerin oranı sadece $\% 0,4$ olarak bulunmuş ve kadınlar bilgisayar bilimleri mezunlarının sadece \%14'ünü oluşturmuştur (Alvarado, Dodds, ve Libeskind-Hadas, 2012; Patitsas, Craig, ve Easterbrook, 2014). Kadınların erkeklere oranla programlamaya yönelik daha düşük tutumu, yetersiz temsil edilmelerinin nedeni olarak görülmektedir (Stroilescu ve Egodawatte, 2010). Başer (2013b), Özyurt ve Özyurt (2015) ve Stoilescu ve Egodawatte (2010), erkeklerin programlamaya yönelik tutumlarının kadınlardan daha olumlu olduğunu bildirmektedirler. Güncel bir çalışmada Du ve Wimmer (2019), kadınların programlama başarısının erkeklerle aynı veya bazı konularda onlardan daha iyi olmasına rağmen erkeklerin bilgisayar programcılığını sürdürmekle daha fazla ilgilendiklerini rapor etmişlerdir. Bu sonuçları raporlayan araştırmalara rağmen, bilgisayar programlamada cinsiyet farklılıklarının genel olarak azaldığı görülmektedir (Alsadoon, 2013; Gurer ve diğerleri, 2019; Top, Yukselturk ve Cakir, 2011). Dahası, baz1 araştırmalar kız öğrencilerin erkek öğrencilere göre daha yüksek programlama başarısına sahip olduklarını göstermektedir (Lau ve Yuen, 2009; Yılmaz, 2013). Bu çelişkili sonuçlar, programlama çalışmalarında cinsiyet faktörünün daha fazla araştırılması gerektiğini göstermektedir.

Öğrencilerin öğrenim gördükleri bölüm de programlama başarısı üzerinde etkili olabilecek faktörlerden biridir. Öğrencilerin üniversiteye giriş sınavında yapmış oldukları bölüm tercihleri onların ilgili alana ve o alandaki konulara olan ilgisi ve tutumu ile ilgilidir (Korkut-Owen, Kepir, Özdemir, Ulaş ve Yılmaz, 2012). Ayrıca, mühendislik fakültesindeki her bölümün programlamaya olan yaklaşımı ve programlama üzerine sunduğu ders sayısı farklılık göstermektedir. Örneğin, Bilgisayar Mühendisliği Bölümünde birçok programlama ve algoritma gibi programlama ile yakın ilişkili ders sunulurken İnşaat Mühendisliği Bölümünde programlama ile ilgili ders sayısı sınırlıdır. Bu durum, hem bölümün programlamaya ilişkin yaklaşımını ortaya koymakta hem de öğrencinin gelecek beklentisini etkilemektedir. Dolayısıyla öğrencilerin bölüm tercihlerinin ve öğrenim gördükleri bölümün onların programlamaya yönelik tutumlarını etkileyeceği tahmin edilmektedir. Gezgin ve Adnan (2016), öğrencilerin programlama öz yeterlikleri ile okumakta oldukları bölüm arasında anlamlı düzeyde ilişki olduğunu saptamıştır. Altun ve Mazman (2012) ve Aşkar ve Davenport (2009) çalışmalarında bilgisayar mühendisliği öğrencilerinin diğer bölüm öğrencilerine göre daha yüksek programlama öz-yeterlik algısına sahip olduklarını sonucuna ulaşmışlardır. Ayrıca Korkmaz ve Altun (2013), bilgisayar mühendisliği öğrencilerinin programlama konusunda diğer mühendislik fakültesi bölüm öğrencilerine göre daha olumlu tutuma sahip olduklarını bulmuşlardır. Benzer şekilde güncel bir çalışmada Gunbatar (2018), Bilgisayar ve Öğretim Teknolojileri Eğitimi (BÖTE) Bölümü öğrencilerinin programlamaya yönelik tutumlarının Bilgisayar Programcılığı öğrencilerinden daha 
yüksek olduğunu ortaya koymuştur. Bu sonuçların aksine Yağc1 (2016), mezuniyete kadar 14 kredilik bilgisayar programlama dersi alan BÖTE öğrencileri ile mezuniyete kadar 31 kredilik bilgisayar programlama dersi alan Bilgisayar Programlama öğrencileri arasında programlamaya yönelik tutum açısından bir fark olmadığını bildirmiştir.

Programlama üzerine sahip olunan deneyimin de programlamaya yönelik tutumu etkileyebilecek potansiyel faktörlerden biri olduğu düşünülmektedir. Programlama üzerine alınan ders sayısının programlamaya yönelik tutum üzerindeki etkisini inceleyen araştırmalara bakıldığında tartışmalı sonuçlar vardır. Godbole (2014) ve Karaci (2016), öğrencilerin programlamaya yönelik tutumunun sinıf düzeyine veya alınan ders sayısına göre farklılık göstermediğini bildirmiştir. Benzer şekilde Gunbatar (2018) ve Gurer ve diğerleri (2019), programlama deneyiminin programlamaya yönelik tutum ile arasında ilişki olmadığını göstermektedir. Bu sonuçların aksine, öğrencilerin programlamaya yönelik tutumunun programlamaya ilişkin alınan ders sayısına göre farklılık gösterdiğini rapor eden çalışmalar vardır (Erol ve Kurt, 2017). Jedege (2009), programlama üzerine alınan ders sayısının programlama öz-yeterliğini yordayan faktörlerden biri olduğu söylemektedir. Özyurt ve Özyurt (2015) da Bilgisayar Programcılığı öğrencilerinin programlamaya yönelik tutumlarının sınıf seviyesine göre önemli farklılıklar gösterdiğini, ikinci sınıf öğrencilerinin birinci sınıf öğrencilerine göre daha olumlu programlama tutumuna sahip olduklarını bildirmektedirler. Bu çelişkili sonuçlar programlama üzerine alınan ders sayısı ile programlamaya yönelik tutum arasındaki ilişkinin daha fazla çalışma ile incelenmesi gerektiğini göstermektedir.

\section{Çalışmanın Amacı}

Programlama öğretiminde karşılaşılan sorunlardan biri, öğrencilerin programlamaya yönelik olumsuz tutumlarıdır (Korkmaz ve Altun, 2013). Bununla birlikte, programlama üzerine yapılan çalışmalar çoğunlukla alternatif öğrenme, bilişsel modeller ve deneyimsiz-uzman programcı karşılaştırmaları gibi bilişsel boyutlarla ilgilidir. Bu nedenle, öğrenci tutumları ile ilgili çalışmaların sayısı sınırlıdır (Cetin ve Ozden, 2015). Duyuşsal öğrenmenin önemli bir bölümünü kapsayan tutumun davranışlarımız üzerinde önemli etkileri vardır ve tutum bilişsel yapımızı şekillendiren önemli bir unsurdur. Dolayısıyla, öğrenme ortamlarında tutumun kapsamlı bir şekilde ele alınması gerekir.

Bilgisayar programlama üzerine yapılan çalışmalar incelendiğinde, bilgisayar bilimlerinden ve programlamadan en çok yararlanan mühendislik fakültesi öğrencilerinin programlamaya yönelik tutumlarını inceleyen çalışmaların eksikliği görülmektedir. Mühendislik fakültesi öğrencilerinin programlamaya yönelik tutumlarının ortaya çıkarılması ve tutumu farklılaştıran faktörlerin incelenmesi, programlama öğretimi yaparken özellikle öğrencilerin tutumunu iyileştirme açısından eğitimcilere yol gösterecektir. Dolayısıyla bu çalışmanın amacı, mühendislik fakültesi öğrencilerinin programlamaya yönelik tutumlarını incelemektir. Bu amaçla araştırmada ele alınan problemler aşağıdaki gibidir:

- Mühendislik fakültesi öğrencilerinin programlamaya yönelik tutumları ne düzeydedir?

- Öğrencilerin programlamaya yönelik tutumları 
- cinsiyetlerine,

- bölümlerine ve

- programlama üzerine aldıkları ders sayılarına göre anlamlı farklılık göstermekte midir?

\section{Evren ve Örneklem}

\section{Yöntem}

Araştırmanın evrenini bir devlet üniversitesinin Mühendislik Fakültesinde okuyan 12.619 lisans öğrencisi oluşturmaktadır. Çalışmanın katılımcıları ise seçkisiz örnekleme ile belirlenen 880 lisans öğrencisinden oluşmaktadır. Gönüllülük esasına dayalı olarak ölçekleri cevaplandıran öğrencilerin yanıtları incelenerek hatalı ya da eksik doldurulan 30 ölçek araştırmadan çıkarılmıştır. Daha sonra verilerin normalliğini sağlamak için uç değerlere sahip (standart puanı $+1,96$ ve $-1,96$ arasında olmayanlar) (Field, 2009) 108 öğrenciye ilişkin veriler araştırmadan çıkarılmış ve çalışmanın katılımcıları 742 lisans öğrencisinden oluşmuştur. Büyüköztürk, KılıçÇakmak, Akgün, Karadeniz ve Demirel'e (2008) göre örneklem sayısının yeterli olduğu söylenebilir. Araştırmaya katılan öğrencilerin demografik bilgilerine ilişkin veriler Tablo 1'de sunulmuştur.

Tablo 1

Örnekleme İlişkin Demografik Veriler

\begin{tabular}{llcc}
\hline Değişkenler & Grup & $\mathbf{N}$ & \% \\
\hline Cinsiyet & Kadın & 204 & 27,49 \\
& Erkek & 538 & 72,51 \\
Bölüm & Bilgisayar Müh. & 54 & 7,28 \\
& Elektrik-Elektronik Müh. & 65 & 8,76 \\
& Endüstri Müh. & 63 & 8,49 \\
& İnşaat Müh. & 69 & 9,30 \\
& Makine Müh. & 64 & 8,63 \\
& Mekatronik Müh. & 95 & 12,80 \\
& Metalurji ve Malzeme Müh. & 68 & 9,16 \\
& Otomotiv Müh. & 46 & 6,20 \\
& Raylı Sistemler Müh. & 72 & 9,70 \\
& Tıp Müh. & 63 & 8,49 \\
& Ulaştırma Müh. & 42 & 5,66 \\
& Çevre Müh. & 41 & 5,53 \\
Programlama üzerine alınan ders & 1 & 340 & 45,82 \\
sayis1 & 2 & 208 & 28,03 \\
& 3 & 122 & 16,44 \\
Toplam (Her bir değişken için) & 4 ve üzeri & 72 & 9,70 \\
& & 742 & 100 \\
\hline
\end{tabular}

Tablo 1'de görüldüğgü üzere araştırmaya katılan öğrencilerin 204'ü $(\% 27,49)$ kadın, 538'i $(\% 72,51)$ ise erkektir. Araştırmaya en fazla katılım 95 kişi ile Mekatronik Mühendisliği bölümünde okuyan öğrencilerden olurken (\%12,80) en az katılım ise 41 kişi ile Çevre Mühendisliği bölümünde okuyan öğrencilerden olmuştur (\%5,53). Araştırmaya katılan öğrencilerden $340^{\prime} 1(\% 45,82)$ bir kez bilgisayar programlama dersi aldıklarını ifade ederken 208'i (\%28,03) iki kez, 122'si $(\% 16,44)$ üç kez ve 72'si $(\% 9,70)$ de en az dört kez bilgisayar programlama dersi aldığını belirtmiştir. 


\section{Veri Toplama Araçları}

Çalışmada kullanılan veri toplama aracı iki bölümden oluşmaktadır. Birinci bölümde cinsiyet, bölüm ve programlama üzerine alınan ders sayısı bilgilerini toplamak için kullanılan maddeler bulunmaktadır. Veri toplama aracının ikinci bölümü ise öğrencilerin programlamaya yönelik tutumlarını ölçmek için kullanılan Cetin ve Ozden'in (2015) geliştirdiği Bilgisayar Programlama Tutum Ölçeği maddelerinden oluşmaktadır. Ölçek bilişsel, duyuşsal ve davranışsal tutumları ölçen 5'li Likert tipinde hazırlanmış ( 1 = Hiç katılmıyorum $-5=$ Tamamen katılıyorum) 18 maddeden oluşmaktadır. Cetin ve Ozden (2015) ölçeğin Cronbach a iç tutarlılık katsayısını 0,93 olarak bulunurken, alt faktörlerin güvenirlik katsayıları bilişsel faktörü için 0,80 , duyuşsal faktörü için 0,90 ve davranışsal faktörü için ise 0,90 olarak hesaplanmıştır. $\mathrm{Bu}$ çalışmada ise ölçeğin tamamının Cronbach a iç tutarlılık katsayısı 0,86 olarak bulunurken, bilişsel, duyuşsal ve davranışsal faktörleri için sırasıyla 0,75, 0,83 ve 0,77 olarak bulunmuştur. Dolayısıyla, Bilgisayar Programlama Tutum Ölçeğinin çalışmanın örneklemi için yüksek güvenirliğe sahip olduğu söylenebilir (Büyüköztürk ve diğerleri, 2008).

\section{Veri Analizi}

Verilerin analizinde ortalama ve standart sapma gibi betimsel istatistiklerle birlikte gruplar arası farkları ölçek için kullanılan Mann-Whitney-U Testi ve Kruskal-Wallis Testinden yararlanılmıştır. Kolmogorov-Smirnov testi sonuçlarına göre (Tablo 2) gruplara ait ölçümler normal dağılıma sahip olmadığından $(\mathrm{p}<0,05)$ gruplar arası karşılaştırmalar için parametrik olmayan testler tercih edilmiştir. Cinsiyete göre farklılaşmayı test etmek için Mann-Whitney-U Testi, bölüme ve programlama üzerine alınan ders sayısına göre farklılaşmayı ölçmek için de Kruskal-Wallis Testi kullanılmıştır. Değerlendirmeler ölçekten elde edilen toplam puan üzerinden değil ortalama puanlar üzerinden gerçekleştirilmiştir. Bilgisayar Programlama Tutum Ölçeği 5’li Likert tipinde bir ölçek olduğundan dolayı ölçekten alınabilecek en düşük puan 1 iken, en yüksek puan da 5 olmaktadır. Testlerden elde edilen ortalama sonuçları yorumlamak için grup aralığı 0,80 olarak belirlenmiştir. Oluşan grupların puan aralıkları 1,00 - 1,80 (çok düşük), 1,81 - 2,60 (düşük), 2,61 - 3,40 (orta), 3,41 - 4,20 (yüksek) ve 4,21 - 5,00 (çok yüksek) olarak belirlenmiştir.

Tablo 2

Kolmogorov-Smirnov Normallik Testi Sonuçları

\begin{tabular}{lccc}
\hline & İstatistik & sd & p \\
\hline Bilişsel &, 058 & 742 &, 000 \\
Duyuşsal &, 096 & 742 &, 000 \\
Davranişsal &, 098 & 742 &, 000 \\
Ortalama &, 037 & 742 &, 019 \\
\hline
\end{tabular}




\section{Bulgular}

\section{Birinci Alt Araştırma Sorusuna İlişkin Bulgular}

Mühendislik fakültesindeki kadın ve erkek öğrencilerin programlamaya yönelik tutumlarına ilişkin betimsel istatistikler Tablo 3'te gösterilmektedir. Ayrıca öğrencilerin programlamaya yönelik tutumlarının cinsiyete göre anlamlı fark gösterip göstermediğine ilişkin araştırma sorusunu cevaplamak için kullanılan Mann-Whitney U-Testi sonuçları Tablo 3'te sunulmuştur.

Tablo 3

Ortalama Puanların Cinsiyete Göre Dağılımı

\begin{tabular}{lllll}
\hline & Cinsiyet & $\mathbf{n}$ & $\overline{\boldsymbol{X}}$ & ss \\
\hline Bilişsel & Kadın & 204 & 3,24 &, 73 \\
& Erkek & 538 & 3,26 &, 72 \\
Duyuşsal & Toplam & 742 & 3,25 &, 72 \\
& Kadin & 204 & 3,36 &, 86 \\
Davranışsal & Erkek & 538 & 3,44 &, 85 \\
& Toplam & 742 & 3,42 &, 53 \\
Tutum (toplam) & Kadin & 204 & 4,21 &, 67 \\
& Erkek & 538 & 4,13 &, 64 \\
& Toplam & 742 & 4,15 &, 55 \\
\end{tabular}

Tablo 3'e göre öğrencilerin bilişsel boyuttaki tutumları $(\bar{X}=3,25)$ orta düzeyde iken duyuşsal $(\bar{X}=3,42)$ ve davranışsal $(\bar{X}=4,15)$ boyutta yüksek düzeydedir. Fakat, duyuşsal boyutta öğrencilerin tutumlarının orta düzeye yakın olduğu da söylenebilir. Ölçeğin bütünü ele alındığında öğrencilerin programlamaya yönelik tutumlarının $(\bar{X}$ $=3,61$ ) yüksek düzeyde olduğu söylenebilir. Öğrencilerin bilişsel boyuttaki tutumlarının diğer boyutlara göre daha düşük olduğu, davranışsal boyutta ise en yüksek ortalamaya sahip olduğu görülmektedir.

Tablo 4

Mann-Whitney U-Testi Sonuçları

\begin{tabular}{llccccc}
\hline & Cinsiyet & $\mathbf{N}$ & $\begin{array}{c}\text { Sıra } \\
\text { ortalamasi }\end{array}$ & $\begin{array}{c}\text { Sıralar } \\
\text { toplamı }\end{array}$ & U & p \\
\hline Bilişsel & Kadın & 204 & 370,46 & 75574,50 & 54664,50 &, 94 \\
& Erkek & 538 & 371,89 & 200078,50 & & \\
Duyuşsal & Kadın & 204 & 360,38 & 73518,00 & 52608,00 &, 38 \\
& Erkek & 538 & 375,72 & 202135,00 & & \\
Davranışsal & Kadın & 204 & 380,30 & 77580,50 & 53081,50 &, 49 \\
& Erkek & 538 & 368,16 & 198072,50 & & \\
Tutum & Kadın & 204 & 369,17 & 75310,00 & 54400,00 &, 86 \\
(toplam) & Erkek & 538 & 372,38 & 200343,00 & & \\
\hline
\end{tabular}

Tablo 4'te görüldüğü üzere hem ölçeğin alt boyutlarında hem de ölçeğin bütünü ele alındığında kadınların ve erkeklerin sıra ortalamaları arasında anlamlı fark 
yoktur ( $\mathrm{p}>0,05)$. Dolayısıyla öğrencilerin programlamaya yönelik tutumlarının cinsiyete göre anlamlı farklılık göstermediği bulgusu ortaya çıkmaktadır.

\section{İkinci Alt Araştırma Sorusuna İlişkin Bulgular}

Mühendislik fakültesi öğrencilerinin programlamaya yönelik tutumlarının öğrencilerin bölümlerine göre anlamlı fark gösterip göstermediğini test etmek için Kruskal-Wallis Testi uygulanmış ve teste ilişkin sonuçlar Tablo $5^{\prime}$ te sunulmuştur.

Tablo 5

Bölümlere Göre Farklılıklan İnceleyen Kruskal-Wallis Testi Sonuçları

\begin{tabular}{|c|c|c|c|c|c|c|}
\hline & Bölüm & $\mathbf{N}$ & $\begin{array}{c}\text { Sira } \\
\text { ortalaması }\end{array}$ & Ki-kare & $\mathrm{p}$ & Anlamlı fark \\
\hline \multirow[t]{12}{*}{ Bilişsel } & (a) Bilgisayar Müh. & 54 & 503,71 & 74,06 & 00 & $a-b, a-c, a-c ̧$, \\
\hline & (b) Elektrik Elektronik Müh. & 65 & 371,18 & & & $a-f, a-h, a-1, a-$ \\
\hline & (c) Endüstri Müh. & 63 & 368,94 & & & $i, a-j, b-c ̧, c-c ̧$, \\
\hline & (ç) İnşaat Müh. & 69 & 244,43 & & & ç-d, ç-e, ç-ff, ç- \\
\hline & (d) Makine Müh. & 64 & 380,48 & & & g, ç-1, e-i, e-j \\
\hline & (e) Mekatronik Müh. & 95 & 458,34 & & & \\
\hline & (f) Metalurji ve Malzeme Müh. & 68 & 371,81 & & & \\
\hline & (g) Otomotiv Müh. & 46 & 406,46 & & & \\
\hline & (h) Raylı Sistemler Müh. & 72 & 311,53 & & & \\
\hline & (1) Tip Müh. & 63 & 379,57 & & & \\
\hline & (i) Ulaştırma Müh. & 42 & 321,67 & & & \\
\hline & (j) Çevre Müh. & 41 & 304,63 & & & \\
\hline \multirow[t]{12}{*}{ Duyuşsal } & $\mathrm{a}$ & 54 & 452,79 & 32,89 & ,00 & $a-c ̧, a-j, c ̧-e, e-$ \\
\hline & $\mathrm{b}$ & 65 & 365,89 & & & $\mathrm{j}$ \\
\hline & c & 63 & 384,64 & & & \\
\hline & ç & 69 & 305,50 & & & \\
\hline & $\mathrm{d}$ & 64 & 388,78 & & & \\
\hline & $\mathrm{e}$ & 95 & 427,14 & & & \\
\hline & $\mathrm{f}$ & 68 & 353,10 & & & \\
\hline & $g$ & 46 & 344,48 & & & \\
\hline & $\mathrm{h}$ & 72 & 369,21 & & & \\
\hline & 1 & 63 & 396,87 & & & \\
\hline & $\mathrm{i}$ & 42 & 326,26 & & & \\
\hline & j & 41 & 280,54 & & & \\
\hline \multirow[t]{12}{*}{ Davranışsal } & a & 54 & 416,82 & 34,97 & 00 & ç-e, e-f, f-h \\
\hline & $\mathrm{b}$ & 65 & 369,10 & & & \\
\hline & c & 63 & 414,71 & & & \\
\hline & ç & 69 & 289,16 & & & \\
\hline & $\mathrm{d}$ & 64 & 372,66 & & & \\
\hline & $\mathrm{e}$ & 95 & 397,99 & & & \\
\hline & $\mathrm{f}$ & 68 & 293,40 & & & \\
\hline & $\mathrm{g}$ & 46 & 398,14 & & & \\
\hline & $\mathrm{h}$ & 72 & 415,19 & & & \\
\hline & 1 & 63 & 408,19 & & & \\
\hline & $\mathrm{i}$ & 42 & 312,70 & & & \\
\hline & $\mathrm{j}$ & 41 & 351,35 & & & \\
\hline Tutum & a & 54 & 480,62 & 61,01 & 00 & $a-c ̧, a-f, a-h$, \\
\hline \multirow[t]{4}{*}{ (toplam) } & $\mathrm{b}$ & 65 & 365,50 & & & $a-i, a-j, c ̧-c, c ̧-$ \\
\hline & c & 63 & 386,73 & & & d, ç-e, ç-1, e-f, \\
\hline & ç & 69 & 257,76 & & & $e-i, e-j, 1-j$ \\
\hline & d & 64 & 380,98 & & & \\
\hline
\end{tabular}




\begin{tabular}{lcc}
\hline e & 95 & 452,91 \\
$\mathrm{f}$ & 68 & 331,62 \\
$\mathrm{~g}$ & 46 & 384,50 \\
$\mathrm{~h}$ & 72 & 359,10 \\
$\mathrm{1}$ & 63 & 402,11 \\
$\mathrm{i}$ & 42 & 312,02 \\
$\mathrm{j}$ & 41 & 289,09 \\
Toplam & 742 & \\
\hline
\end{tabular}

Tablo 5'e göre hem alt boyutlarda hem de ölçeğin tamamında öğrencilerin programlamaya yönelik tutumları bölümlerine göre anlamlı farklılık göstermektedir (Ki-kare bilişsel $=74,06$, Ki-kare duyuşsal $=32,89$, Ki-kare davranışsal $=34,97$, Ki-kare tutum $=61,01, \mathrm{p}<0,05)$. Gruplar arası karşılaştırmalar için Mann-Whitney U-testi sonuçlarına göre Bilgisayar mühendisliği bölümü öğrencilerinin tutumlarının İnşaat, Metalurji ve Malzeme, Raylı Sistemler, Ulaştırma ve Çevre Mühendisliği bölümü öğrencilerinin tutumlarından anlamlı olarak yüksek olduğu görülmektedir. Diğer yandan İnşaat mühendisliği öğrencilerinin tutumları Endüstri, Makine, Mekatronik ve Tıp Mühendisliği öğrencilerinin tutumlarından anlamlı olarak daha düşüktür. Özellikle bilişsel boyutta Bilgisayar mühendisliği bölümü öğrencilerinin tutumlarının Makine, Mekatronik, Otomotiv ve T1p mühendisliği bölümü hariç diğer bölüm öğrencilerinden anlamlı olarak daha yüksek olduğu sonucu ortaya çıkmaktadır ( $\mathrm{p}<$ $0,05)$.

\section{Üçüncü Alt Araştırma Sorusuna İlişkin Bulgular}

Mühendislik fakültesi öğrencilerinin programlamaya yönelik tutumlarının öğrencilerin programlama üzerine aldıkları ders sayısına göre anlamlı fark gösterip göstermediğini test etmek için Kruskal-Wallis Testi uygulanmış ve sonuçlar Tablo 6'da sunulmuştur.

Tablo 6

Alınan Ders Sayısına Göre Farklılıkları İnceleyen Kruskal-Wallis Testi Sonuçları

\begin{tabular}{|c|c|c|c|c|c|c|}
\hline & Ders sayıs1 & $\mathbf{N}$ & Sira ortalamasi & Ki-kare & p & Anlamlı fark \\
\hline \multirow[t]{5}{*}{ Bilişsel } & Bir & 340 & 331,98 & \multirow[t]{5}{*}{32,77} & \multirow[t]{5}{*}{, 00 } & 1 ders-2 ders, \\
\hline & İki & 208 & 380,84 & & & 1 ders-3 ders, \\
\hline & Üç & 122 & 402,17 & & & 1 ders- 4 ders, \\
\hline & Dört & 72 & 479,17 & & & 2 ders-4 ders, \\
\hline & Toplam & 742 & & & & 3 ders- 4 ders \\
\hline \multirow[t]{5}{*}{ Duyuşsal } & Bir & 340 & 356,01 & \multirow[t]{5}{*}{8,27} & \multirow[t]{5}{*}{,06 } & \\
\hline & İki & 208 & 361,68 & & & \\
\hline & Üç & 122 & 407,10 & & & \\
\hline & Dört & 72 & 412,69 & & & \\
\hline & Toplam & 742 & & & & \\
\hline \multirow[t]{5}{*}{ Davranışsal } & Bir & 340 & 341,74 & \multirow[t]{5}{*}{12,95} & \multirow[t]{5}{*}{,01 } & 1 ders- 2 ders, \\
\hline & İki & 208 & 387,67 & & & 1 ders-3 ders, \\
\hline & Üढ̧ & 122 & 406,22 & & & 1 ders- 4 ders \\
\hline & Dört kez & 72 & 406,51 & & & \\
\hline & Toplam & 742 & & & & \\
\hline \multirow[t]{5}{*}{ Tutum (toplam) } & Bir & 340 & 336,60 & \multirow[t]{5}{*}{23,09} & \multirow[t]{5}{*}{,00 } & \multirow{5}{*}{$\begin{array}{l}1 \text { ders-3 ders, } \\
1 \text { ders- } 4 \text { ders }\end{array}$} \\
\hline & İki & 208 & 376,43 & & & \\
\hline & Üç & 122 & 417,14 & & & \\
\hline & Dört & 72 & 444,76 & & & \\
\hline & Toplam & 742 & & & & \\
\hline
\end{tabular}


Kruskal-Wallis testi sonuçlarına göre programlama üzerine 3 veya 4 ders alan öğrencilerin programlamaya yönelik tutumları 1 ders alan öğrencilerin tutumlarından anlamlı olarak daha yüksektir (Ki-kare $=23,09, \mathrm{p}<0,05)$. Bilişsel boyutta ise programlama üzerine daha fazla ders alan öğrencilerin tutumlarının daha yüksek olduğu görülmektedir (Ki-kare $=32,77, \mathrm{p}<0,05)$. Duyuşsal boyutta öğrencilerin tutumlarının aldıkları ders sayısına göre değişmediği görülmektedir (Ki-kare = 8,27, p $>0,05)$. Davranışsal boyutta programlama üzerine 1 ders alan öğrencilerin tutumlarının daha fazla sayıda ders alan öğrencilerden daha düşük olduğu sonucu ortaya çıkmaktadır (Ki-kare $=12,95, \mathrm{p}<0,05)$.

\section{Tartışma}

$\mathrm{Bu}$ çalışma programlama öğretiminin önemli bir yere sahip olduğu mühendislik eğitiminde, öğrencilerin programlamaya yönelik tutumlarını belirlemeyi hedeflemektedir. Çalışmanın sonuçları, mühendislik fakültesi öğrencilerinin programlamaya yönelik tutumlarının pozitif olduğunu ve bu tutumların bölüme ve programlama üzerine alınan ders sayısına göre farklılaştığını göstermektedir. Fakat programlamaya yönelik tutumlar öğrencilerin cinsiyetine göre anlamlı bir farklılık göstermemektedir.

$\mathrm{Bu}$ araştırmaya göre mühendislik fakültesi öğrencilerinin bilgisayar programlamaya yönelik olumlu tutumlara sahip oldukları söylenebilir. Bu sonuç literatürdeki bazı çalışmalar ile benzerlik göstermektedir (Anastasiadou ve Karakos, 2011; Korkmaz ve Altun, 2013; Gurer ve diğerleri, 2019). Öğrencilerin tutumları duyuşsal ve davranışsal boyutlarda yüksek düzeyde iken, bilişsel boyutta orta düzeyde olarak bulunmuştur. Bu sonuç programlamanın öğrenciler tarafından zor bir beceri olarak görüldüğünü ortaya koymaktadır. Genel olarak tutum yüksek düzeyde olmasına rağmen bilişsel boyutta tutumun orta düzeyde olması öğrencilerin programlamayı beklediklerinden daha zor bir süreç olarak görmeleri ile açıklanabilir (Dasuki ve Quaye, 2016).

Araştırmanın bulgularından biri, mühendislik fakültesi öğrencilerinin programlamaya yönelik tutumlarının cinsiyete göre anlamlı farklılık göstermediğini ortaya koymaktadır. Tutumun alt boyutları olan bilişsel, duyuşsal ve davranışsal boyutta da cinsiyete göre farklılık bulunmamıştır. Mevcut çalışmanın bu bulgusuna benzer şekilde, erkeklerin ve kadınların programlamaya yönelik tutumlarının anlamlı bir fark göstermediğini ortaya koyan çeşitli çalışmalar bulunmaktadır (Erol ve Kurt, 2017; Godbole, 2014; Yağcı, 2016). Bu sonuçların aksine, bazı çalışmalar erkek öğrencilerin tutumlarının kız öğrencilere göre anlamlı derecede daha yüksek olduğunu göstermektedir (Başer, 2013b; Karaci 2016; Özyurt ve Özyurt, 2015). Araştırmacılar bilgi ve iletişim teknolojileri alanlarında cinsiyete göre farklılıklar bulmuş olsalar da mevcut çalışmada görüldüğü gibi cinsiyet farkı son birkaç yılda azalmıştır (Alsadoon, 2013; Gurer ve diğerleri, 2019). Gurer ve diğerlerine (2019) göre bu sonuç son yıllardaki bilgi-işlemsel düşünme hareketi ile açıklanabilir. Son yıllarda dünyada bilgi-işlemsel düşünme üzerine olan ilgide artış görülmektedir. Bu ilgi ve eğilim ile birlikte Türkiye'de de öğrenciler tarafından hakkında olumlu görüşler belirtilen farklı programlama platformları kullanılmaya (Çatlak, Tekdal ve Baz, 2015) başlamıştır. Sadece erkeklerin değil kadınların da programlama üzerine eğitim 
almaları ve bu konuda deneyim kazanmaları, cinsiyetin programlamaya yönelik tutum üzerine etkisinin azalmasına neden olmuş olabilir.

Mühendislik fakültesi öğrencilerinin programlamaya yönelik tutumları öğrenim gördükleri bölümlerine göre farklılık göstermektedir. Bilgisayar mühendisliği öğrencilerinin diğer birçok bölüm öğrencileri ile karşılaştırıldığında daha pozitif tutuma sahip oldukları görülmektedir. Bunun aksine, İnşaat mühendisliği öğrencilerinin tutumlarının da diğer bölüm öğrencilerine göre daha düşük olduğu sonucuna ulaşılmaktadır. Bilişsel boyutta ve ölçeğin genelinde bu farklılıklar belirgin bir şekilde ortaya çıkmaktadır. Benzer şekilde Altun ve Mazman (2012) ve Aşkar ve Davenport (2009), bilgisayar mühendisliği öğrencilerinin programlama öz yeterlik algılarının diğer bölüm öğrencilerine göre daha yüksek olduğunu bulmuşlardır. Korkmaz ve Altun (2013) da bilgisayar mühendisliği öğrencilerinin programlamaya yönelik tutumlarının elektronik mühendisliği ve BÖTE bölümlerinde öğrenim gören öğrencilerin tutumlarından daha yüksek olduğunu sonucuna ulaşmışlardır. Bu sonucun sebebi öğrencilerin bölümlerinin programlamaya verdiği önem, bölümlerde sunulan dersler ve mezun olduklarında çalışacakları iş alanı ile ilgili olabilir. Bilgisayar mühendisliği bölümünde sunulan dersler genel olarak yazılım, programlama, algoritma, bilgisayar ağları, veri tabanı yöneticiliği ve gömülü sistemler üzerinedir. Diğer bölümlerle karşılaştırıldığında programlama ve buna ilişkin derslerin sayısının bilgisayar mühendisliği bölümünde daha fazla olduğu ve programlamaya daha çok önem verdiği söylenebilir. İnşaat mühendisliği ise malzeme ve tekniği bir araya getirerek bina, köprü, yol vb. yapıların plan, proje, yapım ve denetlemesiyle uğraşan bilim dalı olarak programlamaya diğer bölümler kadar önem vermemektedir. Dolayısıyla inşaat mühendisliği öğrencilerinin programlamaya yönelik tutumları diğer bölüm öğrencilerinden daha düşük çıkmıştır. Ayrıca bilgisayar mühendisliği bölümü öğrencileri potansiyel bilgisayar bilimcileridir veya büyük olasılıkla bilgi ve iletişim teknolojileri ile ilgili bir meslekte çalışacaklardır. Bilgisayar mühendisliği öğrencilerinin programlamayı gelecek yaşantıları için önemli bir kazanım olarak gördükleri ve bu sebeple programlamaya yönelik yüksek tutuma sahip oldukları düşünülebilir.

Öğrencilerin programlamaya yönelik tutumları programlamaya yönelik aldıkları ders sayısına göre anlamlı farklılık göstermektedir. Programlama üzerine daha fazla sayıda ders alan öğrencilerin tutumları daha az ders alan öğrencilerin tutumlarından daha yüksektir. Diğer bir deyişle, alınan ders sayısı arttıkça programlamaya yönelik tutumda da artış gözlenmektedir. İlgili literatür bu bulgu üzerine çelişkili sonuçlar sunmaktadır. Godbloe (2014) ve Karaci (2016) programlamaya yönelik tutumunun sınıf düzeyine veya alınan ders sayısına göre farklılık göstermediği sonucuna ulaşırken, Özyurt ve Özyurt (2015), programlamaya yönelik tutumun sınıf seviyesine göre anlamlı fark göstermediğini rapor etmişlerdir. Ayrıca Jedege (2009), programlama üzerine alınan ders sayısının programlama özyeterliğini yordayan faktörlerden biri olduğunu belirtmiştir. İlk kez programlama dersi alan öğrenciler temel kavramları anlamada ve başlangıç düzeyindeki derslerde hatasız program yazmada zorlanmaktadırlar (Dasuki ve Quaye, 2016). Ayrıca yeni başlayanlar programlamayı karmaşık bir görev olarak algılamakta, bir programdaki bağlamsal eylemleri anlayamamakta ve açıklayamamaktadırlar. Bu yüzden, öğrenciler programlama sırasında doğru sözdizimi kurallarını uygulayamaz ve yeni 
problemleri çözmek için program yazarken anlamsal programlama bilgisini kullanamazlar (Ismail, Ngah ve Umar, 2010). Yaşadıkları bu zorluklar onların programlamaya yönelik olumsuz tutum geliştirmelerine neden olmaktadır. Öğrenciler daha fazla sayıda programlama dersi aldıklarında ve bu derslerde başarılı olduklarında programlamaya yönelik daha pozitif tutumlar geliştirmektedirler.

\section{Sonuç ve Öneriler}

Sonuç olarak bu çalışma, mühendislik fakültesi öğrencilerinin programlamaya yönelik tutumlarının olumlu olduğunu göstermektedir. Öğrenciler bilişsel düzeyde orta derecede tutuma sahip olsa da duyuşsal ve davranışsal olarak yüksek düzeyde olumlu tutuma sahiptirler. Öğrenciler, programlamaya karşı olumlu duygulara sahip olmalarına ve programlamayı öğrenmek istemelerine rağmen programlamayı zor bir süreç olarak görmektedirler. Bu sonuç, programlama öğrenmede öğrencileri zorlayan veya yanlış öğrenmelerine sebep olan faktörlerin kapsamlı bir şekilde ortaya konması ve bu konular üzerine etkili öğretim yapılması gerektiğini göstermektedir.

İnşaat mühendisliği öğrencilerinin programlamaya yönelik tutumları, mühendislik fakültesinin diğer bölümlerindeki öğrencilerin tutumlarından daha düşüktür. Bu sonuç bölümün doğasının programlamaya verdiği önem ve dersi yürüten öğretim üyesi gibi sebeplerle açılanabilir. Fakat günümüzde özellikle mühendislik için büyük bir önemi olan programlama becerisinin ve bununla birlikte programlamaya yönelik olumlu tutumun geliştirilmesi önemlidir. Dolayısıyla mühendislik fakültelerinin bütün bölümlerinde programlama becerileri bölümün yapısı ve mesleğin ihtiyaçları doğrultusunda geliştirilmelidir. Olumlu tutumu düşük olan bölümlerdeki programlama derslerinde Scratch, Logo veya Small gibi ortamlar kullanılarak (Yukselturk ve Altiok, 2016) öğrencilerin programlamaya yönelik olumlu tutumları geliştirilebilir.

Birçok çalışmanın olduğu gibi bu çalışmanın da birkaç sınırlılığı bulunmaktadır. Örneklem yöntemi olarak rastgele örnekleme seçildiği için verilerin toplandığı örneklem, cinsiyet, bölüm ve programlama üzerine alınan ders sayısı gibi grupların evren içindeki oranlarını yeterince temsil edememiş olabilir. Sonraki araştırmalar grupların evrenini temsil edecek şekilde tabakalı örnekleme yöntemi kullanılarak gerçekleştirilebilir ve parametrik testler kullanılarak analizler gerçekleştirilebilir. Ayrıca bu çalışma, sadece bir üniversitenin mühendislik fakültesinde yürütülmüştür. Daha geniş katılımcı grubu ile çalışarak genellemeler yapabilmek için farklı üniversitelerin mühendislik fakültelerinden de öğrenciler seçilerek çalışmalar gerçekleştirilebilir. Böylece, üniversiteler arası karşılaştırmalar da yapılabilir. Bu araştırmada değişkenlerden birisi öğrencilerin programlamaya yönelik almış oldukları ders sayısıdır. Programlama dillerinin yapılarının ve doğalarının birbirinden farklılık gösterdiği düşünüldüğünde dersi alınan programlama dili öğrencilerin programlamaya yönelik tutumunu etkileyebilir. Bu yüzden, sonraki bir çalışmada programlamaya yönelik tutumun programlama diline göre değişip değişmediği incelenebilir. Çalışmaya göre, İnşaat mühendisliği öğrencilerinin programlamaya yönelik tutumları diğer bölüm öğrencilerinden daha düşük çıkmıştır. Bu sonucun sebebi daha kapsamlı olarak araştırılabilir. Son olarak, öğrencilerin bilişsel boyuttaki tutumlarının orta düzeyde çıkmasının sebepleri ve öğrencileri programlama 
derslerinde zorlayan konuların belirlenmesi nitel çalışmalar ile detaylı bir şekilde araştırılmalıdır.

\section{Kaynakça}

Abdunabi, R., Hbaci, I, and Ku, H-Y. (2019). Towards enhancing programming selfefficacy perceptions among undergraduate information systems students. Journal of Information Technology Education: Research, 18, 185-206. https:// doi.org/10.28945/4308

Aiken, L. (2002). Attitudes and related psychosocial constructs: Theories, assessment, and research. California, USA: Sage Publications.

Alsadoon, E. A. (2013). Factors influencing faculty to adopt web applications in their teaching. Unpublished PhD Thesis, Ohio University, $\mathrm{OH}$.

Altun, A., and Mazman, S. G. (2012). Programlamaya ilişkin öz yeterlilik algısı ölçeğinin Türkçe formumun geçerlilik ve güvenirlik çalışması. Eğitimde ve Psikolojide Ölçme ve Değerlendirme Dergisi, 3(2), 297-308.

Alvarado, C., Dodds, Z., and Libeskind-Hadas, R. (2012). Increasing women's participation in computing at Harvey Mudd College. ACM Inroads, 3(4), 55-64. http:/ / dx.doi.org/10.1145/2381083.2381100.

Anastasiadou, S. D., and Karakos, A.S. (2011). The beliefs of electrical and computer engineering students' regarding computer programming. The International Journal of Technology, Knowledge and Society, 7(1), 37-51. https://doi.org/10.18848/1832-3669/CGP/v07i01/56170

Aşkar, P., and Davenport, D. (2009). An investigation of factors related to selfefficacy for java programming among engineering students. The Turkish Online Journal of Educational Technology, 8(1), 26-33.

Başer, M. (2013a). Attitude, gender and achievement in computer programming. Middle-East Journal of Scientific Research, 14(2), 248-255.

Başer, M. (2013b). Bilgisayar programlamaya karşı tutum ölçeği geliştirme çalışması. The Journal of Academic Social Science Studies, 6(6), 199-215. https:// doi.org/10.9761/JASSS1702

Büyüköztürk, Ş., Kılıç Çakmak, E., Akgün, Ö. E., Karadeniz, Ş., ve Demirel, F. (2008). Eğitimde bilimsel araştırma yöntemleri. Ankara: Pegem Yayınları.

Cetin, I., and Ozden, M. Y. (2015). Development of computer programming attitude scale for university students. Computer Applications in Engineering Education, 23(5), 667-672. doi:10.1002/cae.21639

Çatlak, Ş., Tekdal, M. ve Baz, F. Ç. (2015). Scratch yazılımı ile programlama öğretiminin durumu: Bir doküman ïnceleme çalışması. Journal of Instructional Technologies \& Teacher Education, 4(3), 13-25.

Dasuki, S., and Quaye, A. (2016). Undergraduate students' failure in programming courses in institutions of higher education in developing countries: A Nigerian perspective. The Electronic Journal of Information Systems in Developing Countries, 76(1), 1-18. https:/ / doi.org/10.1002/j.1681-4835.2016.tb00559.x

Doube, W., and Lang, C. (2012). Gender and stereotypes in motivation to study computer programming for careers in multimedia. Computer Science Education, 22(1), 63-78. https:/ / doi.org/10.1080/08993408.2012.666038

Du, J., and Wimmer, H. (2019). Hour of Code: A study of gender differences in computing. Information Systems Education Journal, 17(4), 91-100. 
Erol, O., and Kurt, A. A. (2017). Investigation of CEIT students' attitudes towards programming. Mehmet Akif Ersoy Üniversitesi Eğitim Fakültesi Dergisi, 1(41), 314-325. https://doi.org/10.21764/efd.64721

Field, A. (2009). Discovering Statistics Using IBM SPSS Statistics (4th Ed.). California, USA: Sage Publications

Gezgin, D. M. ve Adnan, M. (2016). Makine mühendisliği ve ekonometri öğrencilerinin programlamaya ilişkin öz yeterlik algılarının incelenmesi. Ahi Evran Üniversitesi Kırşehir Ĕ̆itim Fakültesi Dergisi (KEFAD), 17(2), 509-525.

Godbole, S. (2014). Impact of a visual programming experience on the attitude toward programming of introductory undergraduate students. Unpublished Master's thesis, Purdue University, IN.

Gunbatar, M. S. (2018). Examination of undergraduate and associate degree students' computer programming attitude and self-efficacy according to thinking style, gender and experience. Contemporary Educational Technology, 9(4), 354-373. https:// doi.org/10.30935/cet.471004

Gurer, M. D., Cetin, I., and Top, E. (2019). Factors affecting students' attitudes toward computer programming. Informatics in Education, 18(2), 281-296. https:// doi.org/10.15388/infedu.2019.13

Ismail, M. N., Ngah, N. A. and Umar, I. N. (2010). Instructional strategy in the teaching of computer programming: a need assessment analyses. The Turkish Online Journal of Educational Technology, 9(2), 125- 131.

Jedege, P. O. (2009). Predictors of Java programming self-efficacy among engineering students in a Nigerian university. International Journal of Computer Science and Information Security, 4(1and2).

Karaci, A. (2016). Investigation of attitudes towards computer programming in terms of various variables. International Journal of Programming Languages and Applications (IJPLA), 6(1/2), 1-9. https:/ / doi.org/10.5121/ijpla.2016.6201

Korkmaz, Ö. ve Altun, H. (2013). Mühendislik ve BÖTE öğrencilerinin bilgisayar programlama öğrenmeye dönük tutumları. International Journal of Social Science, 6(2), 1169-1185.

Korkut-Owen, F., Kepir, D., Özdemïr, S., Ulaş, Ö., ve Yılmaz, O. (2013). Üniversite öğrencilerinin bölüm seçme nedenleri. Mersin Üniversitesi Eğitim Fakültesi Dergisi, 8(3), 135-151.

Lau, W. W. F. and Yuen, A. H. K. (2009). Exploring the effects of gender and learning styles on computer programming performance: Implications for programming pedagogy. British Journal of Educational Technology, 40(4), 696-712. https:// doi.org/10.1111/j.1467-8535.2008.00847.x

Lee, S., Kim, J., and Lee, W. (2017). Analysis of factors affecting achievement in maker programming education in the age of wireless communication. Wireless Personal Communications, 93(1), 187-209. https:/ / doi.org/10.1007/s11277-0153166-8

Naraghi, M. H. N., and Bahman, L. (2001). An effective approach for teaching computerprogramming to freshman engineering students. Proceedings of the 2001 American Society for Engineering Education Annual Conference and Exposition. https:/ / doi.org/10.18260/1-2--9162 
Özyurt, Ö., and Özyurt, H. (2015). A study for determining computer programming students' attitudes towards progmming and their programming self-efficacy. Journal of Theory and Practice in Education, 11(1), 51-67.

Patitsas, E., Craig, M., and Easterbrook, S. (2014). A historical examination of the social factors affecting female participation in computing. In Proceedings of the 2014 conference on innovation and technology in computer science education (111116). New York, NY, USA: ACM. http:// dx.doi.org/10.1145/2591708.2591731.

Singh, K., Allen, K. R., Scheckler, R., and Darlington, L. (2007). Women in computerrelated majors: A critical synthesis of research and theory from 1994 to 2005. Review of Educational Research, 77(4), 500-533. https:// doi.org/10.3102/0034654307309919

Sölpük N. (2017). The effect of attitude on student achievement. In: Karadag E. (eds) The Factors Effecting Student Achievement. Springer, Cham. https://doi.org/10.1007/978-3-319-56083-0_4

Stoilescu, D., and Egodawatte, G. (2010) Gender differences in the use of computers, programming, and peer interactions in computer science classrooms. Computer Science Education, 20(4), 283-300. https:// doi.org/10.1080/08993408.2010.527691

Tebliğler Dergisi (2012). T.C. Tebliğler Dergisi. 01/05/2019 tarihinde http:/ / tebligler.meb.gov.tr/index.php/tuem-sayilar/finish/76-2012/3262662-kas-m-2012 adresinden alınmıştır.

Top, E., Yukselturk, E., and Cakir. R. (2011). Gender and Web 2.0 technology awareness among ICT teachers. British Journal of Educational Technology, 42(5), E106-E109 https:/ / doi.org/10.1111/j.1467-8535.2011.01208.x

Wing, J. M. (2008). Computational thinking and thinking about computing. Philosophical Transactions of the Royal Society A: Mathematical, Physical and Engineering Sciences, 366, 3717-3725. https://doi.org/10.1098/rsta.2008.0118

Yağcı, M. (2016). Bilişim teknolojileri (BT) öğretmen adaylarının ve bilgisayar programcilığı (BP) öğrencilerinin programlamaya karşı tutumlarının programlama öz yeterlik algılarına etkisi. Journal of Human Sciences, 13(1), 1418-1432. https:// doi.org/10.14687/ijhs.v13i1.3502

Yılmaz, F. (2013). Meslek yüksek okulu öğrencilerinin programlama başarısını etkileyen faktörlerin incelenmesi. Yayımlanmamış Yüksek Lisans Tezi, Gazi Üniversitesi, Ankara.

Yukselturk, E., and Altiok, S. (2016). An investigation of the effects of programming with Scratch on the preservice IT teachers' self-efficacy perceptions and attitudes towards computer programming. British Journal of Educational Technology, 48, 789-801. https:// doi.org/10.1111/bjet.12453

Zyda, M. (2009). Computer science in the conceptual age. Communications of the ACM, 52(12), 66-72. https://doi.org/10.1145/1610252.1610272

\section{Summary}

\section{Introduction}

Literature has indicated that psychological factors such as negative perception, motivation and especially low attitudes are the factors that negatively affect 
programming achievement. Research on computer programming also emphasizes the positive relationship between programming attitude and success (Gurer, Cetin, and Top, 2019; Lee, Kim and Lee, 2017). Therefore, the attitude towards programming that affects programming skills and success needs to be further investigated.

One of the potential factors related to students' programming success is gender. Özyurt and Özyurt (2015) and Stoilescu and Egodawatte (2010) reported that males' attitudes towards programming are more positive than females. Despite the studies reporting these results, gender differences in computer programming has decreased (Alsadoon, 2013; Gurer et al., 2019).

Students' department is also one of the factors that can affect the success of programming. Gezgin and Adnan (2016) found that there is a significant correlation between students' self-efficacy and their department. In addition, Korkmaz and Altun (2013) found that computer engineering students had more positive attitudes towards programming than other engineering students.

It is considered that the programming experience is one of the potential factors that might affect the attitude towards programming. Godbole (2014) and Karaci (2016) reported that students' attitudes towards programming did not differ according to grade level or the number of courses taken. Contrary to these studies, there are studies reporting that students' attitudes towards programming differ according to the number of lessons taken on programming (Erol and Kurt, 2017).

Attitude, which covers a significant part of affective learning, has important effects on behaviors, and attitude is an important element shaping cognitive structure. Examining the attitudes of engineering students towards programming and the factors that differentiate the attitudes will guide the instructors in improving students' attitudes while teaching programming. Therefore, the aim of this study is to examine the attitudes of engineering students towards programming. For this purpose, the problems addressed in the research were as follows:

- What is the attitude of engineering students towards programming?

- Is there a significant difference in students' attitudes towards programming in terms of:

- gender,

- department, and

- the number of programming courses?

\section{Method}

The participants of this study were 742 students of an engineering faculty in a university at West Black Sea Region. Of the participants, 204 (27.49\%) of them were female and 538 (72.51\%) were male.

To collect data Computer Programming Attitude Scale (Cetin and Ozden, 2015) was used. The scale consisted of 18 items in 5-point Likert-type within three constructs. In this study, Cronbach a internal consistency coefficient of the whole scale was found to be 0.86 . Additionally, it was found to be $0.75,0.83$ and 0.77 for cognitive, affective and behavioral factors, respectively.

To analyze data, in addition to descriptive statistics such as mean and standard deviation, non-parametric tests, Mann-Whitney-U and Kruskal-Wallis, were used to compare group scores. 


\section{Results}

According to the results of the data analysis;

- Engineering students' attitudes towards computer programming were at moderately high level $(\bar{X}=3.61)$. While their attitudes were at moderately high level in affective $(\bar{X}=3.42)$ and behavioral $(\bar{X}=4.15)$ dimensions, their attitudes were at moderate level $(\bar{X}=3.25)$.

- There was not a significant difference in the mean scores of males and females in terms of attitude toward programming (Mann-Whitney- $\mathrm{U}=$ 54400.00, $\mathrm{p}>0.05)$ and its sub-dimensions ( $\mathrm{p}>0.05)$.

- There was a significant difference in the scores of students at different departments in terms of attitude toward programming (Chi-square $=61.01$, $\mathrm{p}<0.05)$ and its sub-dimensions $(\mathrm{p}<0.05)$.

- There was a significant difference in engineering students' attitudes towards programming according to the number of courses they took on programming in total score and in cognitive and behavioral dimensions $(p$ $<0.05)$. There was not a significant difference in the affective dimension ( $p$ $>0.05)$.

\section{Discussion}

The results of the study showed that engineering students have positive attitudes towards programming. The attitudes of the students were found to be high in affective and behavioral dimensions and moderate in cognitive dimension. Although the attitude is generally high, the moderate level of cognitive attitude can be explained by the fact that students see programming as a more difficult process than they expect (Dasuki and Quaye, 2016).

One of the findings of the study indicated that the students' attitudes towards programming did not differ significantly in terms of gender. There were no differences in the cognitive, affective and behavioral dimensions, either. According to the Gurer et al. (2019), this result can be explained by the computational thinking movement in recent years. With this trend and interest, different programming platforms have been used in programming courses (Çatlak, Tekdal and Baz, 2015). The fact that not only males but also females receive training on programming and gain experience might reduce the effect of gender on the attitude towards programming.

Engineering students' attitudes towards programming showed significant differences in terms of their department. It was seen that computer engineering students have a more positive attitude compared to many other departmental students. On the contrary, it was concluded that the attitudes of the students of Civil Engineering were lower than the students of other departments. The reason for this result might be related to the importance given by the departments to the programming, the courses offered in the departments and the field of work students would work upon graduation.

Lastly, students' attitudes towards programming differed significantly in terms of the number of courses they took on programming. Students who took more courses on programming had higher attitudes than students who took less courses. In other words, as the number of lessons taken on programming increased, so did the attitude towards programming. 


\section{Pedagogical Implications}

Based on the results summarized above, it is suggested that:

- Average level of engineering students' cognitive attitude implies that the topics and the skills the students had difficulties would be determined and instructors focus more on those issues to increase their attitude and achievement in programming.

- Several programming platforms such as Scratch, Logo or Small have been found to enhance students' attitudes towards programming. Instructors of programming courses at engineering faculties would integrate those tools into their teaching.

One of the results of this study showed that students who had less computer programming lessons had lowest attitudes toward programming. Instructors of these students could consider this result in designing their courses to increase their attitudes and to continue on programming.

\section{Araştırmanın Etik İzinleri}

Yapılan bu çalışmada "Yükseköğretim Kurumları Bilimsel Araştırma ve Yayın Etiği Yönergesi" kapsamında uyulması belirtilen tüm kurallara uyulmuştur. Yönergenin ikinci bölümü olan "Bilimsel Araştırma ve Yayın Etiğine Aykırı Eylemler" başlığı altında belirtilen eylemlerden hiçbiri gerçekleştirilmemiştir.

Etik kurul izin bilgileri

Etik değerlendirmeyi yapan kurul adi = Bolu Abant İzzet Baysal Üniversitesi Sosyal Bilimlerde İnsan Araştırmaları Etik Kurulu

Etik değerlendirme kararının tarihi= 09.07.2018

Etik değerlendirme belgesi sayı numarası= Protokol NO. 2018/139

\section{Authors' Biodata/ Yazar Bilgileri}

Melih Derya GÜRER Bolu Abant İzzet Baysal Üniversitesi Eğitim Fakültesi Bilgisayar ve Öğretim Teknolojileri Eğitimi Bölümünde Dr. Öğr. Üyesi olarak görev yapmaktadır. Çalışma yaptığı konular arasında çevrimiçi öğrenme, eğitimde teknoloji entegrasyonu ve Web 2.0 teknolojileri gelmektedir.

Melih Derya Gürer works as an assistant professor at the Department of Computer Education and Instructional Technology in Faculty of Education of Bolu Abant Izzet Baysal University. His studies inclue online learning, technology integration into education, and Web 2.0 technologies.

Seyfullah TOKUMACI İzmir Bakırçay Üniversitesinde öğretim görevlisi olarak görev yapmaktadır. Bilgisayar ve Öğretim Teknolojileri Eğitimi alanında yüksek lisans derecesine sahiptir.

Seyfullah Tokumacı works as an instructor at İzmir Bakırçay University. He has a master degree in Computer Education and Instructional Technology field. 